\title{
A COMPOSIÇÃO DO TEMPO SOCIAL DE MULHERES PROFESSORAS DURANTE A PANDEMIA
}

Recebido em: 30/12/2020

Aprovado em: 02/02/2021

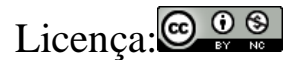

Amanda Raquel Rodrigues Pessoa ${ }^{1}$

Marla Maria Moraes Moura ${ }^{2}$

Instituto Federal do Ceará (IFCE)

Juazeiro do Norte - Ceará - Brasil

Isabel Maria Sabino de Farias ${ }^{3}$

Universidade Estadual do Ceará (UECE)

Fortaleza - Ceará - Brasil

RESUMO: Esta pesquisa analisa a composição do tempo social de mulheres professoras no período de isolamento social imposto pela pandemia da COVID-19, especificamente a relação do ensino remoto com aspectos do cuidado de si, das obrigações domésticas e familiares, do trabalho e do lazer. Pautada numa abordagem com enfoque qualitativo e quantitativo, 44 mulheres responderam a um questionário misto, sendo a análise pautada na análise de conteúdo de Bardin (2011). Os resultados revelaram que o ensino remoto comprometeu o tempo social em virtude da ampliação, intensidade e das condições de trabalho. Os afazeres domésticos e familiares ainda permaneceram sob a responsabilidade das mulheres, comprometendo o lazer. Concluise que o tempo social no contexto pandêmico intensificou a sensação de sobrecarga e evidenciou a divisão desigual dos papeis sociais.

PALAVRAS-CHAVE: Mulher Professora. Atividades de Lazer. COVID-19.

\section{THE COMPOSITION OF THE SOCIAL TIME OF TEACHING WOMEN DURING THE PANDEMIC}

\footnotetext{
${ }^{1}$ Doutoranda em Educação pela Universidade Estadual do Ceará (UECE). Mestre em Educação pela Universidade Federal do Ceará (UFC). Professora do Instituto Federal do Ceará (IFCE). Líder do Grupo de Estudos, Pesquisa e Extensão em Educação, Corporeidade e Sociedade (GEPEECOS). Pesquisadora colaboradora no Grupo de Pesquisa Educação, Cultura Escolar e Sociedade (EDUCAS).

2 Mestre em Educação pela Universidade Federal do Pernambuco (UFPE). Professora do Curso de Licenciatura em Educação Física do Instituto Federal do Ceará (IFCE). Pesquisadora do Grupo de Estudos, Pesquisa e Extensão em Educação, Corporeidade e Sociedade (GEPEECOS).

${ }^{3}$ Possui Estágio Pós-Doutoral em Educação pela Universidade de Brasília (UNB); Doutorado e mestrado em Educação Brasileira pela Universidade Federal do Ceará (UFC). Professora da Universidade Estadual do Ceará (UECE). Líder do grupo de pesquisa Educação, Cultura Escolar e Sociedade (EDUCAS) e membro do grupo de estudo e pesquisa Formação de Professores e Práticas de Ensino (FOPPE/UFSC).
} 
ABSTRACT: This research analyzes the composition of the social time of female teachers in the period of social isolation imposed by the pandemic of COVID-19, specifically the relationship of remote education with aspects of self-care, domestic and family obligations, work and leisure. Based on an approach with a qualitative and quantitative approach, 44 women answered a mixed questionnaire and the analysis was based on content analysis Bardin (2011). The results revealed that remote education compromised social time due to the expansion, intensity, and working conditions. Household and family chores still remained under the responsibility of women, compromising leisure. It is concluded that social time in the pandemic context intensified the feeling of overload and shows the unequal division of social roles.

KEYWORDS: Woman Teacher. Leisure Activities. COVID-19.

\section{Introdução}

Este artigo procura discutir a composição do tempo social de mulheres professoras diante do período de distanciamento social imposto pela pandemia da COVID-194 . As políticas de isolamento social adotadas para reduzir a disseminação do vírus alteraram o formato de ensino, sendo incluído o ensino remoto emergencial como alternativa de proteger profissionais de educação e comunidade escolar.

O Ensino Remoto Emergencial (ERE) até então não era disseminado entre a maioria dos docentes, o que gerou inicialmente muita insegurança e questionamentos sobre o seu formato e acessibilidade entre professores e estudantes. Behar (2020) atribui o caráter excepcional desse modelo de ensino e esclarece que a sua existência se justifica por um impedimento por decreto da realização das aulas em formato presencial.

Em complementação, Alves (2020) apresenta que na atual configuração as práticas pedagógicas dos professores foram reconfiguradas para adequar-se às

\footnotetext{
${ }^{4}$ A COVID-19, transmitida pelo novo coronavírus, é uma doença respiratória que teve foco inicial em Wuhan (China) em dezembro de 2019, vindo a se disseminar rapidamente por vários países, tendo sido declarada, em 11 de março 2020, pela Organização Mundial da Saúde - OMS, como pandemia. No Brasil, o primeiro caso da doença foi identificado em 26 de fevereiro de 2020 na cidade de São Paulo. Até 23 de dezembro de 2020,f oram confirmados 7.365.517 casos da doença e 189.220 óbitos. Protocolos sanitários continuam sendo implantados na tentativa de conter o surto da doença. Recentemente, o governo estabeleceu o plano de vacinação contra a COVID-19.
} 
plataformas digitais que viabilizassem o acesso dos alunos. Hodges et al. (2020) ressaltam diferenças entre esse modelo e a educação à distância (EAD), destacando que a EAD conta com recursos e uma equipe preparada para a oferta da modalidade, o que não acontece na estrutura do ERE por ser uma alternativa temporária movida por circunstâncias de crise social e sem preparação prévia para a sua execução.

O ensino remoto ressoou em várias frentes muitos questionamentos sobre sua acessibilidade diante do quadro de desigualdade social vivenciado no país, além disso, os professores se viram diante de um modelo pouco explorado e, para alguns, desconhecido, prevalecendo a urgente necessidade de formação para a realização do ensino remoto, o que não aconteceu como política nacional, colocando a responsabilidade nas mãos dos estados, dos gestores e, sobretudo, dos professores.

O fato é que o ERE entrou como estratégia para a manutenção das práticas pedagógicas e do calendário escolar e adentrou na casa e na vida cotidiana dos professores e das professoras. As políticas de isolamento social mudaram a organização do trabalho docente, alterando as práticas cotidianas de viver fenômenos como trabalho e lazer.

Essas alterações não foram escolhas, mas uma imposição social do Estado visando amenizar os impactos do vírus na saúde pública. As obrigações sociais e as práticas de lazer passam a coexistir no mesmo tempo e espaço. O lar passou a se configurar como um ambiente de múltiplas dimensões sociais e o único lugar seguro para viver socialmente.

Com a inviabilidade do modelo presencial para a organização do trabalho docente, que já tinha antes da pandemia a característica de sobrecarga de horas fora daquelas realizadas no ambiente escolar, o ambiente doméstico assume completamente a carga laboral. E, diante disso, a composição de tempo para viver formas de 
organização social que se aproximem das características que compõem o lazer passam a ser objeto de análise desse presente estudo. Se, para autores como Marcellino (2012) e Camargo (2003), o tempo livre é o tempo vivido fora das obrigações laborais e o tempo do lazer é composto por um grau de escolha pessoal e liberdade visando um bem-estar, prazer de forma gratuita, torna-se relevante questionar como fica a composição do tempo social diante dos limites e inusitadas situações que o contexto de pandemia impôs.

A mulher trabalhadora se transforma no foco dessa discussão, pois acredita-se que as diferenças de gênero afetam a composição do tempo de lazer (MARCELLINO, 2012), uma vez que já se iniciam desde a infância com a construção dos papéis e comportamentos sociais e se intensificam com o processo de socialização.

Gurgel (2010) analisa a marginalização da mulher no contexto social e ressalta que nas relações de produção ela não possui total liberdade de escolha sobre as deliberações que gostaria de realizar, algumas atribuições são fortemente marcadas por imposições sociais que retiram, por meio de um controle social, o poder de escolha sobre seu corpo, seu trabalho e a organização do seu tempo.

A trajetória de inclusão da mulher no trabalho é um campo dotado de lutas e conquistas, sua presença nesses ambientes é resultado de resistência a uma sociedade patriarcal movida por preceitos tradicionais de condutas e de crenças, na qual ainda impera uma responsabilização das obrigações familiares e domésticas no cotidiano feminino, estando a inserção da mulher no mercado de trabalho marcada por progressos e atrasos (BRUSCHINI, 2007). Vive-se momentos de transformações no que se refere à inclusão da mulher no mercado de trabalho, no entanto, como analisa Maruani (1993), estes ainda não se caracterizam como rupturas, mas constituem-se em "brechas", 
decisivas e fundamentais para o movimento feminista, porém ainda inacabadas, incompletas e dotadas de significações desiguais e precárias sobre a mulher.

Partindo dessa conjuntura, questiona-se sobre a organização do tempo da mulher professora para viver momentos de lazer, especificamente sobre como ela vem organizando seu tempo no cenário social da pandemia e se as obrigações estão permitindo viver formas de lazer. Dito isso, é preciso considerar que o uso do termo lazer vem sendo utilizado por ser este o conceito que melhor representa a ideia de pensar o uso do tempo como espaço de prática e fruição, visando o bem-estar e o prazer. Sabe-se que a composição limitada de escolhas afeta essa relação, mas, em si, não inviabiliza pensar, dentro do grau de liberdade e escolha que se tem, na composição desse tempo dentro da esfera do lazer.

Para pensar o conceito de lazer, esteve-se apoiado nas propriedades tratadas por autores clássicos como Dumazedier (1994) e em autores brasileiros como Marcellino (2012) e Camargo (2003). Estes defendem um conceito de lazer na sua relação com o trabalho, sendo a vivência do lazer analisada a partir de categorias como tempo, escolha pessoal, atitude, liberdade, gratuidade, prazer, podendo ser praticado ou fruído.

É preciso ponderar também que a noção de tempo em uma sociedade movida pelos interesses econômicos se pauta numa relação estreita, linear, mecânica e repetitiva que, por vezes, retira a possibilidade de ampliação das escolhas e de novas formas de viver esse novo tempo.

Durante a pandemia, por alguns instantes, talvez tenha ocorrido a ilusória sensação de que ficar em casa ocasionaria em maior tempo disponível para viver outras possibilidades de sua organização. No entanto, o setor econômico, de forma rápida, procurou se ajustar às demandas do momento e assim incluiu o trabalho na dinâmica do ambiente doméstico, procurando manter um ritmo de produtividade durante um período 
humanamente difícil de fragilidades emocionais. Com esses ajustes, se evidencia a força produtiva como dominante do ritmo social, o tempo se submete aos ordenamentos financeiros e as pessoas cada vez mais se distanciam da possibilidade de controlar seu próprio tempo. Como analisam Werneck; Stoppa e Isayama (2001), o tempo é o instrumento que regulariza o mercado, é o meio de exploração do trabalho, é tratado como dinheiro e de forma sutil comanda a trama social em que está inserido. $\mathrm{O}$ tempo reina como organismo regulador de comportamentos, atitudes, papéis sociais, ele foi fragmentado para atender aos interesses do trabalho e em sua forma naturalizada há pouco tempo para viver a vida fora da lógica do capital. Nesse sentido, o tempo de lazer se estrutura a partir do tempo livre disponibilizado pelo trabalho (MARCELLINO, 2012).

A força do tempo produtivo transformou o tempo de lazer em mercadoria e este também passou a ser um tempo de consumo, previsível, controlado e pago pelo trabalho. Essa conjuntura vai ao encontro da afirmação de Marcellino (2012) quando aponta o fator econômico como determinante para a distribuição do tempo disponível entre as classes sociais. Sendo assim, o tempo de trabalho se impôs ao ambiente do lar no período de pandemia, visando manter a produtividade e essa realidade adentra nas profissões, em particular quando pretende-se analisar o contexto vivido na profissão docente.

Vale ressaltar que o trabalho docente possui características de organização e relações sociais específicas, se constitui em uma profissão movida por interações humanas, com demandas que ultrapassam o ambiente laboral, sendo comum encontrar profissionais com acúmulos de trabalho que adentram em suas rotinas pessoais. Autores como Nóvoa (2007), Formosinho (2009), Tardif e Lessard (2012) ressaltam que a composição subjetiva constitui a profissão docente, sendo sua função de ensinar 
movida, ao mesmo tempo, por dimensões intelectuais, pedagógicas, artesanais, artísticas, éticas, afetivas e sociais. Por conseguinte, este estudo parte da ideia de que as atividades materiais e simbólicas que perpassam o trabalho das professoras se intercruzam com a vida cotidiana e com os novos cenários que se apresentam.

A docência se configura como uma esfera profissional de estreita relação com a inclusão da mulher no ambiente laboral, dentre as profissões, é aquela que foi rapidamente associada ao contexto feminino como possibilidade de trabalho. No entanto, cumpre evidenciar que, inicialmente, a docência não foi pensada como carreira adequada para mulher. Foi a possibilidade de conciliar a atuação docente com as atividades domésticas e de garantir mão de obra para a educação primária, contexto pouco procurado por homens, que assegurou a oportunidade da mulher exercer uma profissão que não interferiria no papel de esposa e de mãe (BRABO, 2005).

Na análise de Chamon (2005), a aceitação no magistério liga-se às exigências na profissão de um corpo profissional comprometido com a disciplinarização e o cuidado com as crianças. Na conjuntura social, sua inclusão foi movida por discursos que alimentaram o estereótipo da mulher como possuidora de uma vocação "natural" para cuidar de crianças e uma superioridade nas relações afetivas. Além disso, “[...] era preciso de um corpo estável de profissionais que não buscasse no salário o motivo de seu ofício" (CHAMON, 2005, p. 80).

Essa relação estreita da mulher com a profissão docente impulsionou a escolha do público a ser analisado, além de ser uma profissão dotada de interações sociais e, por isso, flexível ao que acontece na sociedade. Como afirmam Tardife Lessard (2011, p. 43), ensinar “[...] é agir dentro de um ambiente complexo e, por isso, impossível de controlar inteiramente, pois, simultaneamente, são várias as coisas que se produzem em diferentes níveis de realidade". E, considerando isso, diante de um contexto de 
pandemia, como fica a relação da mulher com o trabalho docente? Como seu tempo, a sua rotina, precisaram se ajustar a essa nova realidade? Como fica o tempo de lazer diante da entrada do trabalho no ambiente doméstico?

Esses questionamentos se intensificam na relação com as características que cada profissão assume, o que perfaz a sua profissionalidade irá impactar nesse cenário. Nesse sentido, a profissão docente tem peculiaridades que se somam à problemática em estudo,sendo um aspecto relevante a se considerar na relação entre tempo de trabalho e de lazer.

Acredita-se que o ensino remoto modifica essa estrutura de relações profissionais. Com a pandemia, o ensino passa a ser realizado em um novo formato e a distribuição e organização do tempo se intercruzam de maneira peculiar, intensificando as relações do trabalho com a vida pessoal. Em meio à rotina do lar, nem sempre possível de ser silenciada, ocorre a interação das professoras com os alunos, modificando as formas de ensinar e aprender.

Assim, considerando esse universo problematizador, o artigo tem como objetivo analisar a composição do tempo social de mulheres professoras no período de isolamento social imposto pela pandemia da COVID-19, especificamente a relação do ensino remoto com aspectos do cuidado de si, das obrigações domésticas e familiares, do trabalho e do lazer.

O interesse por essa temática parte das experiências vividas pelas autoras em tempos de ensino remoto e isolamento social, circunstâncias que alteraram os modos de ensinar e aprender ao estabelecerem novas demandas e configurações. Esta pesquisa se justifica ainda pelo fato de contribuir para a ampliação das reflexões acerca da composição do tempo social de mulheres professoras mediante os desafios do ensino 
remoto imposto pela pandemia da COVID-19 no Brasil e suas correlações com as demais atividades desempenhadas.

\section{Percursos Metodológicos}

A trilha metodológica deste estudo se pautou em uma abordagem com enfoque qualitativo e quantitativo, se caracterizando como um método misto de pesquisa (SAMPIERI; COLLADO; LUCIO, 2013). Faz-se um levantamento de informações sobre a organização do tempo social de mulheres professoras e procura-se analisar as perspectivas e compreensões que elas fazem sobre essa atual forma de viver as relações de trabalho e lazer. Acredita-se que a união de perspectivas metodológicas nesta pesquisa favorece a ampliação e a compreensão sobre o fenômeno, possibilitando uma melhor análise e discussão dos resultados.

O público da pesquisa foi composto por 44 mulheres professoras que atuam em uma instituição pertencente à rede Federal de Ensino no Estado do Ceará. O estado do Ceará, localizado na região Nordeste do Brasil, vem se destacando como um dos estados com maior índice de contaminação da COVID-19, sendo as políticas de isolamento social seguidas por decretos desde 16 de março de 2020. $\mathrm{O}$ ensino remoto na instituição pesquisada teve adesão em 27 de julho de 2020 e continua a ser o único meio de realização das atividades docentes até a finalização do ano de 2020.

Adotou-se como procedimento de coleta de dados o questionário virtual desenvolvido na Plataforma Google Forms, a opção se deve ao fato de ser este instrumento virtual uma possibilidade segura para as políticas de saúde e de rápida disseminação em redes sociais e plataformas de comunicação. Como etapa para o processo de divulgação, criou-se um link de acesso que foi enviado em grupos do 
aplicativo Whats App relacionados à Instituição e via e-mail para as professoras atuantes.

A plataforma Google Forms permite organizar o questionário com perguntas fechadas e abertas, com possibilidade de múltiplas escolhas, respostas longas e curtas,o que permitiu pensar em um questionário semiestruturado, composto por 12 perguntas. $\mathrm{O}$ instrumento contemplou questões voltadas para a caracterização do grupo investigado com dados gerais e em seguida se direcionou para categorias previamente pensadas envolvendo a caracterização das mulheres professoras: a composição do seu tempo social em relação a aspectos como cuidados de si, obrigações domésticas e familiares, trabalho e lazer e as implicações na vida cotidiana e, por fim, a relação do trabalho docente remoto com a organização do seu tempo social, especificamente a relação das obrigações sociais com o lazer.

Procurando seguir aspectos éticos na pesquisa, junto ao link de divulgação continha um texto introdutório explicando o teor da pesquisa, assegurando o anonimato e as finalidades acadêmicas do estudo. Além do texto introdutório, o primeiro aspecto contido no questionário era o TCLE, que pode ser acessado de forma online pelo link do Google Drive, e, em seguida, pediu-se a confirmação do aceite em divulgar o conteúdo fornecido para os fins da pesquisa. Desse modo, essa investigação se ampara na Resolução $\mathrm{n}^{\circ}$ 510, de abril de 2016, que trata do agir ético do pesquisador, tendo em vista a necessidade de garantir o pleno exercício dos direitos dos participantes (BRASIL, 2016).

O questionário foi aplicado no mês de dezembro de 2020, esse período foi escolhido por se tratar de um tempo de finalização do ano letivo, se configurando como um momento de maior visão sobre o cenário vivido durante o ano. Teve-se o retorno de 44 questionários, os quais foram analisados tendo como fundamento a análise de 
conteúdo proposta por Bardin (2011), procurando realizar as três etapas denominadas de:1) pré-análise; 2) exploração do material e 3) o tratamento dos resultados, a inferência e a interpretação.

Para Bardin (2011), a pré-análise trata da organização propriamente dita, que consiste na escolha dos documentos, através dos critérios de exaustividade, representatividade, homogeneidade e pertinência; no resgate das hipóteses e objetivos; na elaboração dos índices e na preparação do material. A segunda fase, a exploração do material, refere-se à análise do material selecionado, transformando-o em núcleos de sentidos por meio da codificação, decomposição ou enumeração. Na última fase, os dados são tratados para que se tornem significativos.

Procurou-se realizar uma análise de forma comprometida com o referencial teórico que alimenta esta discussão, cruzando os dados obtidos com o que se tem na literatura, aliando a isso as posições e compreensões sobre o objeto dos pesquisadores, o que será apresentado a seguir.

Os resultados e discussões foram organizados com a seguinte composição discursiva: a) Apresentação das professoras; b) A composição do tempo social das professoras durante a pandemia; c) $\mathrm{O}$ lazer das mulheres professoras durante a pandemia; d) O trabalho docente remoto e as implicações na organização do tempo social de lazer.

\section{Resultados e Discussões}

De início, pretende-se apresentar as professoras a partir de alguns aspectos sociais que podem, no decorrer da análise, representar um elemento variante na discussão e desencadear processos reflexivos necessários quando se analisa as relações 
de trabalho e lazer em mulheres professoras. Estes se referem a idade, estado afetivo, quantidade de filhos, idade dos filhos e nível de formação profissional.

\section{a) Apresentação das Professoras}

No que tange a idade das professoras, doze (12) estão entre 26 e 35 anos, vinte e quatro (24) entre 36 e 45 anos; seis (06) entre 46 e 55 anos e duas (02) com 55 anos ou mais. Considerando esse aspecto, as professoras desta investigação estão em sua maioria em uma fase da vida considerada de maior produtividade. Segundo Pronovost (2011), a faixa etária que vai dos 25 aos 44 anos tem frequentemente as porcentagens mais altas de tensão e falta de tempo. Na esfera pessoal, essa fase se destaca por ser um período de consolidação de um novo grupo familiar, sendo comum a ocorrência de casamentos e nascimento dos filhos.

Sobre as características de formação familiar, a resposta das professoras da pesquisa, quando questionadas sobre a situação afetiva e a presença de filhos, vai ao encontro da análise de Pronovost (2011), sendo a maioria (28) 63,7\% casadas, (03) 6,8\% encontra-se em união estável, (04) 9,1\% estão namorando e (09) 20,5\% são solteiras. No que se refere à presença de filhos, (26) 59,1\% declaram que possuem filhos e (18) 40,9\% não possuem. Das professoras que declararam ter filhos treze (13) têm um filho, onze (11) têm dois filhos, uma (01) tem três filhos e uma (01) mais de 3 filhos. A faixa de idade dos filhos foi bastante variada, com a presença de filhos em fases de desenvolvimento diferentes em cada família. Na família das professoras encontram-se dez (10) que possuem crianças com faixa-etária de 0 a 5 anos, seguidas de oito (08) com idade entre 06 a 10 anos, quatro (04) com idades de 11 a 15 anos, três (03) com idade entre 16 a 20 anos e sete (07) acima de 20 anos. 
As professoras também foram questionadas sobre o nível de formação profissional: $38,6 \%$ (17) possuem doutorado, 52,2\% (23) mestrado, seguidos de $6,8 \%$ (03) com especialização e 2,3\% (01) com graduação. O nível de instrução das professoras demonstra o quanto a mulher tem procurado se aperfeiçoar nas atividades laborais, representando uma constante busca de legitimidade nos espaços de atuação profissional e uma crescente qualificação profissional.

Tendo apresentado o perfil social das professoras da pesquisa, segue-se com a análise dos resultados referentes à distribuição do tempo social das professoras a partir de uma análise do tempo dedicado a atividades domésticas, familiares, cuidados de si, trabalho e lazer. Diante desse levantamento, também se questionou as professoras sobre as implicações dessa distribuição do tempo na sua vida pessoal, em particular nas suas vivências de lazer.

\section{B) A Composição do Tempo Social das Professoras Durante a Pandemia}

Perguntou-se às professoras quanto tempo, distribuídos em horas diárias, dedicavam às atividades domésticas. Esse questionamento busca dialogar com o que vem sendo expresso na literatura em que se discute a presença ainda de forma predominante dessas obrigações no universo feminino (GARCIA, 2009). O que encontrou-se como resultado apresentou que 20,5\% (09) passam 6 horas (diárias) ou mais realizando atividades domésticas, 11,4\% (05) passam 5 horas (diárias), 18,2\% (08) passam 4 horas (diárias), 13,6\% (06) passam 3 horas (diárias), 15,9\% (07) 2 horas (diárias), 4,5\% (02) 1 hora (diária), 6,8\% (03) menos de 1 hora (diária), 4,6\% (02) não realizam diariamente, 2,3\% (01) não realiza obrigações domésticas e 2,3\% (01) realiza o dia todo, por isso não consegue mensurar. 
Observa-se que há um predomínio de professoras com dedicação às atividades domésticas, demonstrando que as mulheres ainda possuem uma quantidade de horas consideravelmente alta para dedicação às obrigações do lar. Semanalmente, a maioria das professoras do estudo dedica, em média, 35 horas ou mais do seu dia às atividades domésticas. Apesar do estudo de Soares (2008) apontar que os afazeres domésticos de mulheres reduzem um pouco quando possuem ensino superior, observa-se que este aspecto não foi predominante nos resultados encontrados. Acredita-se que outros fatores acentuados na pandemia podem influenciar nesses resultados, como o isolamento social decretado e as mudanças econômicas geradas com a situação social.

As professoras também foram questionadas sobre o tempo diário dedicado a obrigações familiares no contexto de pandemia. Como resultado obteve-se: 18,2\% (08) 6 horas ou mais, 13,6\% (06) 4 horas, 18,2\% (08) dedicam 3 horas, 22,7\% (10) 2 horas, 13,6\% (06) 1 hora, 9,1\% (04) menos de uma hora, 2,3\% (01) não tem como mensurar, e 2,3\% (01) não tem obrigações familiares.

Os dados demonstram uma carga de horas elevada sobre a mulher, as obrigações familiares, assim como as domésticas, geram uma sobrecarga semanal bastante intensa, apesar disso observa-se entre as professoras que na distribuição do tempo se sobressaem as atividades domésticas.

Com o isolamento social, acredita-se que a convivência familiar aumentou e isso pode ter sido um elemento significante na pesquisa para a ocorrência de uma distribuição do tempo de dedicação às obrigações familiares com menor expressividade entre as mulheres professoras. Além disso, como salienta Pronovost (2011), os homens vêm assumindo de forma mais significativa alguns papéis sociais como a paternidade, o que também pode contribuir na distribuição das horas.

Ainda assim, destaca-se que os homens dedicam menos tempo para a realização 
de afazeres domésticos e obrigações familiares quando comparados a mulheres em situação ocupacional semelhante (BRASIL, 2019). Partindo dessa perspectiva, Oliveira (2020) verifica, em pesquisa desenvolvida recentemente, que as mulheres são as principais responsáveis por realizar os afazeres domésticos e familiares, dedicando $73 \%$ a mais de horas que os homens.

Permanece acentuada a quantidade de horas semanais dedicadas aos cuidados com a família e as obrigações domésticas, para uma parcela dessas mulheres professoras, basta observar que 31,8\% (14) possuem uma média de 25 horas semanais, tempo superior à média nacional de 18,5 horas, enquanto os homens, em igual situação, dedicam apenas 10,3 horas (BRASIL, 2019). Esse dado evidencia ainda que o homem invista prioritariamente o seu tempo no trabalho remunerado na esfera social e pública.

Ademais, esse tempo maior destinado às atividades domésticas e familiares verificado nesta pesquisa, considerando a média nacional, pode ter relação com a pandemia em virtude do isolamento e dos seus impactos nos modos de vida e na ampliação do tempo no ambiente doméstico, a intensificação do convívio familiar requerendo um ritmo mais intenso e acumulando maior número de atribuições.

Considerando a composição do tempo social das professoras, perguntou-se se ocorreu alteração na distribuição do tempo para o cuidado de si na pandemia. Sobre este aspecto, 93,2\% (41) responderam que sim e 6,8\% (03) disseram que não. Os resultados expressam que a pandemia provocou mudanças significativas na relação dessas mulheres com os cuidados voltados para si mesmas. Procurando saber de forma mais contextual sobre essas mudanças, questionou-se as professoras, que responderam se ocorreu modificação (41), quais foram as alterações e como se sentem em relação a essas mudanças. Entre as respostas, observou-se que as mudanças ganharam conotações positivas e negativas, sendo a maioria relacionada a uma diminuição do tempo para o 
autocuidado, com trinta e três (33) professoras ressaltando essa redução, como fica explícito nas respostas:

P03: [...] Como não tenho babá, senti que perdi qualquer liberdade que um dia eu tive e isso me deixa completamente devastada a ponto de pensar que a maternidade piorou meu jeito de ser.

P29: Deixei de frequentar psicóloga, salão de beleza, drenagem, tempo para ler ou ouvir música ou "não fazer nada" não existe mais.

P16: Disponho de menos tempo para mim e para meus filhos! Sinto-me culpada, mas são tantos afazeres que acabam misturando-se que fica muito difícil equilibrar.

P31: Passo o dia cuidando da casa e dos filhos, salvo dar aula, qualquer outro trabalho é feito de madrugada.

P32: Não tenho conseguido fazer atividade física com frequência. Tenho passado muitas horas sentada por conta das atividades de reuniões, planejamentos e aulas remotas. Minha rotina mudou muito, dessa forma tenho sentido dores na coluna, o grau da minha miopia aumentou, percebo que o desgaste psicológico aumentou em detrimento das muitas atividades.

P28: Inicialmente, no isolamento social houve a proibição severa do contato social e agora ainda há cautela e/ou proibição e isso interferiu/interfere no autocuidado. Autocuidado este que na minha vida diz respeito a: convivência social com amigos e familiares (festinhas/ reuniões/ saídas a bares/restaurante); a não poder ou ter restrições em fazer práticas corporais coletivas e individuais (dança, natação e musculação); e falta/limitação de serviços de estética ou bem estar (depilação/manicure/corte de cabelo-salão/massagem). Associado a tudo isso, o medo/pânico generalizado das mortes de modo maciço que deixa todos os autocuidados parecendo de certa forma egoístas ou supérfluos diante da pandemia.

Três (03) professoras demonstraram ter ficado em estado de alerta sobre as alterações do tempo social durante a pandemia e procuraram realizar o autocuidado para buscar manter a saúde, apesar de expressarem também sentir dificuldades de organizar o seu tempo.

P22: O tempo ainda é escasso, mas vou tentando priorizar espaços na agenda para o descanso e cuidado pessoal, por ter notado o aumento da ansiedade e depressão nesse isolamento e excesso de trabalho.

P15: Devido ao aumento de atividades remotas, minha saúde teve complicações e tive que dispensar muito mais tempo de autocuidado e tratamento, tomando o tempo do trabalho e estudo, muitas vezes.

Como aspectos positivos provocados pelo contexto de pandemia na relação com 
o autocuidado, cinco (05) professoras destacaram aspectos como: maior contato familiar, participar de cursos e palestras e retornar costumes ou atividades. A resposta da professora P12 expressa bem essa relação: "P12: Melhorou. Voltei a fazer coisas que não conseguia como fazer exercício físico, assistir filmes e séries, participei de cursos e palestras interessantes, fiquei mais perto de minhas filhas".

O contexto atual trouxe a possibilidade das professoras refletirem sobre as suas carências anteriores à pandemia, emergindo interesses e necessidades que não se encaixavam na rotina de trabalho e demais demandas. Cabe ressaltar que apenas cinco professoras apontaram aspectos positivos, demonstrando ser um reduzido número frente ao total de respostas, estas parecem que conseguiram olhar para si e estabelecer, em meio à rotina, o tempo para o autocuidado que implica desde a prática de atividade física bem como o desenvolvimento pessoal através de práticas formativas e contemplativas.

O maior contato familiar, a possibilidade de estar com os filhos e compartilhar momentos também foram mencionados como fatores positivos pelas mulheres professoras. Com o isolamento social, todos estão em casa, inclusive as crianças que antes passavam significativa parte do tempo na escola, acarretando em mudanças na dinâmica doméstica que implicam em novas estratégias para conciliar diferentes atividades (OLIVEIRA; QUEIROZ; DINIZ, 2020).

As professoras parecem ainda perceber nas atividades em família uma oportunidade de estreitar laços e fortalecer vínculos. Esses momentos puderam ser ampliados, em virtude do aumento do tempo de convivência, mesmo quando acarretam conflito em decorrência de outras demandas, como o exposto por Oliveira (2020, p. 163): “em meio a uma pandemia, e na correria de ser mãe e pesquisadora, não posso mais adiar aquilo que realmente importa: brincar com meu filho e aprender a ver o 
mundo com alguma poesia”.

No entanto, nem todas as mulheres professoras conseguiram realizar o mesmo movimento de aproveitar o tempo para si olhar e atender as suas demandas $\mathrm{e}$ necessidades. Desse modo, sobre a organização do tempo para o cuidado de si, percebese que este foi severamente afetado por questões de ordem emocional, desgaste físico, carga laboral, obrigações domésticas, familiares e restrições sociais. A sua manutenção, quando aconteceu, esteve relacionada mais a uma consciência da necessidade do que mesmo a uma ampliação do tempo. As mudanças provocadas com a pandemia acabaram sobrecarregando o tempo social e impossibilitaram ou reduziram o autocuidado para a maioria das professoras. É interessante notar como o universo das obrigações familiares, domésticas e o trabalho ocupam centralidade no tempo social das professoras mesmo diante de um quadro grave de saúde pública.

Oliveira (2020, p. 160) explicita que as mulheres “[...] sentem-se afetadas pelos rumos que a vida doméstica vem tomando nesse espaço-temporalidade da pandemia. A educação (domiciliar, à distância) soma-se a esta carga de preocupação que acaba por se agravar quando mães são também professoras”.

Diante do quadro de pandemia que já perdura por meses, com fases de isolamento mais restritivas e outras mais flexíveis, o tempo tem ganhado novos contornos, quase não se percebe diferença entre os dias de semana e os finais de semana, feriados ou mesmo férias, pois a rotina só se repete, contribuindo ainda mais com a sensação de sobrecarga.

Com a intensificação dos afazeres e dos cuidados e a desigualdade na divisão do trabalho, a mulher agrega diferentes papéis (trabalhadora, mãe, esposa, dona de casa) que a conduz para o conflito sobre o que priorizar e para a exaustão, considerando os cuidados requisitados pelos familiares e as atribuições profissionais, acarretando numa 
diminuição do tempo para cuidar de si, para descansar, para vivenciar o lazer (PORTO, 2008).

As questões expostas até aqui contribuem para perceber uma sobrecarga sobre o tempo social das professoras, mas, visando saber se estas sentem essa sobrecarga, foi feito o questionamento sobre esse aspecto e como resultado obteve-se 90,9\% (40) que afirmaram se sentir sobrecarregadas, em detrimento de 9,1\% (04) que não sentem esse peso social.

Essa sobrecarga é algo bastante evidente em pesquisas que abordam a organização do tempo social da mulher trabalhadora, esta pesquisa se une a estes levantamentos, como os realizados por Brabo (2005); Porto (2008); Oliveira; Queiroz e Diniz (2020), demonstrando que ainda tem-se como desafio a desconstrução de posturas sociais que naturalizam essas condições de trabalho, que já eram presentes antes da pandemia e parecem ter se acentuado para as professoras participantes desta pesquisa.

Corroborando com os achados desta pesquisa, Brabo (2005) afirma que reduzido número de professoras partilham as atividades domésticas e familiares com maridos e filhos. Balizada em padrões tradicionais, numa divisão desigual do trabalho que incide diretamente no tempo de permanência nos espaços privados, a jornada da mulher professora é estafante, em virtude da sobreposição de jornadas de trabalho vividas no ambiente doméstico. Muitas vezes, a mulher internaliza a responsabilidade desses afazeres, tendo em vista que social e culturalmente vem sendo atribuída a ela o desempenho, quase que exclusivo, dessas tarefas só pelo fato de ser mulher (PORTO, 2008).

Contribuindo com a discussão, Oliveira; Queiroz e Diniz (2020) explicitam que, predominantemente, a responsabilidade pelas tarefas domésticas e familiares recaem sobre as mulheres, constituindo-se enquanto atividade gratuita e sem valorização, 
somando-se às demais demandas do trabalho. E reconhecem que a divisão desigual do trabalho e a naturalização social constituem-se como mecanismos de manutenção e continuidade desses processos de exploração do trabalho feminino, uma vez que estabelecem a expropriação do tempo, de energia e da qualidade de vida.

Com base no exposto, Porto (2008) explica que o fato da sobrecarga das tarefas domésticas e familiares não serem consideradas socialmente como exploração da mulher, posto que se configuram como atividades tradicional e naturalmente destinadas a elas, não retira o peso de todo o tempo destinado por mulheres ao trabalho não remunerado.

Dentro da distribuição do tempo das professoras, foram estabelecidas ainda questões sobre as formas de aproximação com o lazer que as professoras conseguiram realizar em tempo de pandemia. Vejam estes aspectos no item a seguir.

\section{C) O Lazer das Mulheres Professoras Durante a Pandemia}

Sobre a administração do tempo de lazer na pandemia, as professoras responderam que, em sua maioria, 68,2\% (30) não conseguiram conduzir de forma satisfatória e 31,8\% (14) consideram que sim, administraram bem. As principais práticas de lazer realizadas foram organizadas no Quadro a seguir:

Quadro 01: Atividades de Lazer das Professoras durante a Pandemia.

\begin{tabular}{l|c}
\multicolumn{1}{c}{ ATIVIDADES DE LAZER REALIZADAS NA PANDEMIA } & $\mathbf{N}^{\mathbf{0}}$ \\
\hline Assistir (TV, Filmes, séries, Stand-up, lives) & 22 \\
\hline Realizar exercício físico & 15 \\
\hline Socialização com família e amigos & 10 \\
\hline Ler & 09 \\
\hline Brincar com filhos & 08 \\
\hline Ir a espaços livres (praças, praias) & 04 \\
\hline Atividades manuais (desenhar, tocar instrumentos, cuidar de plantas) & 05 \\
\hline Consumo de comidas e bebidas & 03 \\
\hline Ouvir músicas & 01 \\
\hline Nenhuma & 02 \\
\hline
\end{tabular}

Fonte: Organizado pelas autoras a partir dos dados da pesquisa. 
Dentre as atividades de lazer, se destacam as relacionadas ao uso de internet e meios eletrônicos como TV, celular, computadores. Pode-se observar que a pandemia intensificou o uso desses equipamentos como esfera de entretenimento e de lazer, dentro de uma perspectiva de passividade diante do vivido, como analisa Marcellino (2012), o lazer pode ser passivo ou ativo, sendo que o processo criativo é comprometido quando faz-se uso apenas do papel de espectador, sendo necessário manter as formas ativas de aproximação com os equipamentos de lazer.

Como no estudo de Montenegro; Queiroz e Dias (2020) quando analisaram o lazer de um grupo de universitários, as professoras investigadas também demonstraram fazer uso frequente destes equipamentos dentro de uma dimensão virtual, apontando que a virtualidade se transformou em um canal de vivências do lazer.

Por sua vez, 08 (oito) professoras apresentaram o brincar com filhos como forma de lazer, e isso gerou uma reflexão sobre a relação do lazer com a esfera do prazer e das obrigações. Essa associação parece justificar-se pela dimensão hedonista que o elo afetivo da maternidade provoca, mesmo que, junto com isso, outras tensões possam coexistir, como atenção, cuidado, proteção, medo. Além disso, indaga-se se assumir o brincar com filhos como forma de lazer não evidencia a falta de tempo provocada pela maternidade para viver o lazer de forma individual, até que ponto o lazer e o brincar dos filhos é de fato o lazer e o brincar para a mãe. Onde se encontra a mulher, seus gostos e suas vontades nessa relação?

Soma-se ao exposto $\mathrm{o}$ fato das mulheres apresentarem constantemente preocupação com o bem-estar dos filhos, gerando mais responsabilidades e sacrifícios, de modo que parte do seu tempo de lazer acaba sendo absorvido pelas demandas e necessidades dos outros, sobretudo dos filhos. Com isso, a mulher tende a descolar a atenção de si e de suas necessidades, como consequência, torna-se difícil identificar e 
priorizar suas próprias preferências e vivências de lazer.

Perguntou-se às professoras se alguma prática de lazer fora incluída nesse período de isolamento social, quais seriam e quais mudanças. Identificou-se que algumas professoras disseram que não incluíram nada novo (07), as demais destacaram o contato com o lazer virtual (11), atividades físicas (12), culinária (03), brincar com filhos (04), cuidado com plantas (01), ir à praça (01), leitura (01) e algumas não responderam (04). Observa-se nas respostas que a relação com o ambiente virtual se tornou mais intensa, sendo um espaço que ganhou destaque na vida cotidiana, seguido de uma maior relação com o corpo e com a alimentação. Moraes (2020) evidencia que a prática de hobbies, exercícios físicos e alimentação saudável são atividades que contribuem para amenizar os prejuízos à saúde mental provocados pela pandemia e pelo isolamento social.

Algumas respostas serão apresentadas a seguir, procurando mostrar as suas implicações no lazer das professoras:

P28: Sim. Danças por meio de YouTube (fitdance). Foi diferente, mas exigiu minha autorregulação de tempo e determinação para fazer com a frequência desejada para atingir os objetivos de aprender as coreografias, manter-me saudável e ativa, e perder gordura. Porém, sem contato e interação social com professores ou colegas de turmas (já que é tudo individualizado sem feedback).

P27: Sim. Aula de dança com professores de outros estados, assisti trabalhos artísticos de outros estados, entre outras. A pandemia afastou as pessoas do contato físico, que é de extrema importância para todo ser humano, mas diminuiu a distância geográfica-virtual. Durante esse período, conheci muitas pessoas virtualmente, aprendi muito através de congressos, colóquios, lives, grupo de estudos, entre outros.

P10: Sim, a pandemia fez com que organizasse meu cotidiano de forma diferente e reinventasse dentro de casa meios de lazer, como fazer aula de ginástica dentro de casa, assistir mais programas de TV e cozinhar. Além de brincadeiras com minha filha. Vejo as mudanças como meio de questionar nossos costumes, no início foi bem difícil, mas com o tempo vem a adaptação.

As respostas apresentadas evidenciam que entre os conteúdos de lazer vivenciados destacam-se os virtuais, manuais e intelectuais, fortalecendo os achados dos 
estudos de Montenegro; Queiroz e Dias (2020); Teodoro; Brito; Camargo; Silva e Bramante (2020) e Silva; Bergamo; Antunes e Patreze (2020). Mediante o confinamento no lar em razão da pandemia, o lazer virtual tem se constituído como alternativa. De forma abrupta, significativa parcela da população teve que permanecer em seus lares, considerando as medidas sanitárias estabelecidas para trabalhar, estudar, entreter-se, descansar, divertir-se, criar, desenvolver-se etc. O lazer precisou ser ajustado, adaptado e reinventado visando atender às novas condições impostas pela pandemia e pelo isolamento social.

Clemente e Stoppa (2020) afirmam que à medida que atividades como viagens, festas, cinemas, clubes, parques, shoppings foram vedadas ou mesmo restringidas, cresceram as vivências que utilizam o ambiente virtual, recursos tecnológicos e plataformas digitais, como YouTube, Netflix, Globoplay, redes sociais, televisão, encontros online ou reuniões, por meio do Zoom, Google Meet, entre outros. Os recursos tecnológicos vêm oportunizando experiências virtuais como shows, espetáculos, confraternizações, aniversários, encontros entre amigos, estabelecendo um novo formato de socialização, agora virtual. Todavia, o estudo de Schwartz e Moreira (2007) revela que a utilização dos territórios virtuais como espaço e expressão de lazer já vinha se intensificando mesmo antes da pandemia.

No entanto, cabe o alerta estabelecido por Silva; Bergamo; Antunes e Patreze (2020) no que diz respeito à utilização do meio virtual como alternativa de lazer no contexto pandêmico. Os referidos autores advertem que o lazer virtual não deve se restringir a um entretenimento alienante. Sendo assim, as experiências virtuais de lazer precisam vincular-se a uma prática refletida de liberdade, que contribua para o desenvolvimento do senso crítico e criativo e estabeleça uma conscientização de ser e estar no mundo. 
A intensificação no uso das tecnologias viabilizou ainda o desenvolvimento pessoal, à medida que as professoras tiveram a possibilidade de qualificação ampliadas ao longo da pandemia, considerando que foi possível a participação em eventos, grupos de estudos, palestras, cursos, debates etc.

\section{D) O Trabalho Docente Remoto e as Implicações na Organização do Tempo Social}

\section{de Lazer}

Procurando analisar as implicações do ensino remoto na distribuição do tempo social das professoras, questionou-se que percepção tinham sobre o trabalho docente remoto e a organização do tempo social e verificou-se que 41(quarenta e uma) professoras, quase a totalidade das mulheres investigadas, demonstraram em suas respostas que houve comprometimento nessa relação, sendo difícil separar ou conciliar as demandas sociais com o lazer. Abaixo, algumas respostas que representam o contexto de discussão:

P03: Simplesmente não consigo trabalhar com um mínimo de eficiência. A maior parte do meu trabalho é durante a noite, quando as crianças dormem (e quando dormem) sendo os encontros ao vivo realizados com som ao fundo de choro, grito e brigas. Não consegui conciliar o trabalho remoto com nada da minha vida, fiz tudo com uma condição bem menor da capacidade que eu tenho.

P16: Compromete bastante! É um processo de organização desigual, em desequilíbrio... O tempo de trabalho se sobrepõe às outras atividades, inclusive ao tempo social e de lazer. Sinto-me muito culpada! Sensação de "não cumprir meus deveres", mesmo dedicando tanto tempo ao trabalho remoto.

P28: Sim, compromete. Uma vez que este formato é muito mais trabalhoso, muito mais horas são necessários para organizar/confeccionar aulas/realizar aulas e gerir o processo de avaliação/fixação de conteúdo (elaboração e correções de trabalho /exercícios/provas de modo digital) - tudo isso sem formação adequada para alunos e professores pra o uso tecnologia pra o ensino e, associado à "frieza" que este meio, gera diferente das aulas presenciais, que se pode interagir com professor-aluno e aluno-aluno. Todas as necessidades novas geram tempo para produzir trabalho e roubam o tempo livre/lazer.

P34: Compromete sim. Ficou difícil a separação e percepção de cada atividade. A presença da filha em casa e suas solicitações se sobrepunham às atividades domésticas e de trabalho também. Algumas vezes foi necessário 
fazer interrupções de aulas para atender solicitações da filha e da casa também.

P36: O excesso de reuniões, e o tempo para replanejar comprometeram meu tempo livre que eu destinaria aos meus estudos. Então tive que escolher entre dormir ou estudar, o que causou desordem, stress, torcicolo, preocupação etc.

P44: Com certeza o tempo ficou ainda mais comprometido. O trabalho remoto invadiu a privacidade de nossa vida e de nossa família e não respeita horários, os contatos de trabalho são a qualquer dia e qualquer hora.

As respostas evidenciam o quanto o ensino remoto conseguiu comprometer o tempo social. As exigências burocráticas, a necessidade de relação aluno/professor para atingir a aprendizagem, as demandas de planejamento e organização de aulas, se intensificaram nesse novo modelo de trabalho, comprometendo as relações familiares e obrigações domésticas que são, ainda, naturalizadas ao universo feminino. Martins (2020, p. 251) analisa que se intensificou o debate sobre questões antigas e mal resolvidas no cenário educacional, a exemplo de aspectos como “[...] as condições de trabalho do docente, a qualidade do processo de ensino-aprendizagem, a relevância e o significado dos temas a serem abordados, o desenvolvimento de práticas pedagógicas centradas no estudante [...]", sendo que na pandemia estas questões recaíram sobre os lares dos professores alterando e adentrando em um espaço social até então destinado, ao menos com maior prioridade, para a vida pessoal.

O ensino remoto também provocou implicações no estado emocional das professoras, aumentando os níveis de estresse, preocupação, culpa, o que ressoou nas condições físicas, provocando tensão. Nesse sentido, o relato de Oliveira (2020, p. 161) reforça esse entendimento ao estabelecer que "não bastasse a mudança no modo de lecionar, agora novas formas de estresse foram adicionadas ao trabalho docente feito em casa, como ter que gravar aulas virtuais de madrugada enquanto as crianças dormem".

Em tempos em que o ensino remoto ganha protagonismo, novos desafios se somam à prática pedagógica docente, como o de gerenciar no mesmo espaço-tempo as atividades profissionais, as tarefas domésticas e os cuidados familiares. À medida que o 
espaço domiciliar foi transformado em posto de trabalho para desenvolvimento do ensino remoto - home office, novas demandas de ritmo, de responsabilidades e de cobranças foram estabelecidas, resultando numa sobrecarga maior na rotina de trabalho, associada, por vezes, a sentimentos de incapacidade, de incompetência, de culpa. Tais aspectos são preocupantes, tendo em vista que podem acarretar no adoecimento de mulheres.

Ser mulher professora em contexto de pandemia também diminuiu a privacidade e as interações no momento da aula, em contrapartida, ampliou uma atenção virtual individual, indo além dos limites do tempo de dedicação ao ensino remoto. Essas questões evidenciam o quanto a docência é movida por relações humanas que não conseguem ser supridas pela relação estabelecida no momento do ensino, exigindo uma atenção individual a demandas que surgem nessa relação,na qual o professor é ao mesmo tempo pessoa e profissional, não podendo desconsiderar nenhum destes aspectos (NÓVOA, 2007).

A docência em si possui demandas que exigem um compromisso para além do momento de aula, aspecto que se intensificou na pandemia e impactou na organização do tempo social, reduzindo ou retirando do cotidiano as atividades de lazer. Dito isso, cumpre ressaltar que a pandemia provocou uma reestruturação tanto na gestão como na organização do fazer docente e, consequentemente, ampliou a intensidade e a precariedade das condições de atuação profissional ao avultar metas e estender o tempo da jornada de trabalho (SOUZA et al., 2020). O que se percebe é uma corrida pelo retorno da vida produtiva sem pensar nas consequências que isso teria para a vida humana.

Os fatores emocionais, as condições de trabalho e a qualidade com que o ensino passaram a ocorrer precisam ser questões centrais para a composição desse novo 
modelo, pois estes geram consequências na vida cotidiana dos professores, em particular, chama-se atenção aqui ao contexto feminino, por ser este dotado de uma naturalização das sobrecargas sociais, sendo pouco evidenciados seus impactos na vida das mulheres trabalhadoras. Como afirmam Coelho; Silva e Fortes (2012), as questões de gênero, articuladas às configurações do mundo do trabalho e a outras condições sociais como maternidade, se colocam como fatores impeditivos de uma melhor qualidade de vida. Assim, é urgente e necessário evidenciar que estas relações são desiguais, procurando realizar a escuta das mulheres sobre os seus diferentes contextos, a fim de gerar discussões e transformações nesse cenário.

É preciso ponderar também que as 03 (três) professoras que responderam não ocorrer comprometimento na organização do seu tempo social não desconsideraram as implicações do ensino remoto, apenas ressaltaram que conseguem realizar uma distribuição humanamente compatível com o contexto vivido. Dentro das respostas, percebe-se que os aspectos positivos envolvem a possibilidade de viver o contato com o lar e os familiares, bem como desperdiçar menos tempo com deslocamentos para o trabalho.

P27: O trabalho e lazer foram de forma remota. Eu consegui organizar bem, não me privando de atividades programadas como, por exemplo, assistir lives, participar de oficinas corporais, fazer pilates, ter reuniões com família e amigos, entre outros.

P30: Sim! Para melhor! Fico mais tempo em casa! Acompanhando a vida dos meus!

P35: [...] o trabalho remoto está sendo muito proveitoso, uma vez que o tempo gasto com deslocamento e afazeres pessoais é suprimido. Por outro lado, as demandas de poluição sonora e ergonomia dos móveis do lar são pontos negativos para o conforto e concentração para o trabalho remoto. No tocante ao tempo social, esse ficou muito escasso, devido à disseminação avassaladora do vírus.

As respostas das professoras trazem o indicativo de que mesmo no formato presencial há sobrecarga, que há comprometimento das demandas familiares e do lar, o que para algumas foi amenizado por possibilitar um maior tempo junto de familiares 
e maior contato com o lar, o que gera uma percepção positiva sobre o formato remoto de ensino.

Reafirmando essa percepção, a pesquisa de Batista (2020, p. 36) identificou que o home office possibilitou uma economia considerável de tempo destinado ao deslocamento ao ambiente de trabalho, que variou entre 30 minutos a 2 horas, tempo que pode ser aproveitado de outras formas, inclusive contribuindo para que os pais acompanhem e participem mais de perto da rotina dos filhos. Além da otimização do tempo, "a qualidade de vida é impactada com a economia de tempo de trajeto, até porque o trabalhador não se sujeita aos impactos do trânsito, transporte público, clima e poluição". Desse modo, o trabalho remoto evitaria o desgaste físico e mental provocado pelo trânsito enquanto realiza o percurso de casa para o trabalho.

\section{Considerações Finais}

O artigo teve como foco de análise a composição do tempo social de mulheres professoras diante do período de isolamento social imposto pela pandemia de COVID19, perspectivando refletir sobre as implicações nas formas de organização do lazer, do trabalho e dos cuidados com os familiares e consigo.

O ensino remoto foi aplicado de forma emergencial, visando estabelecer a continuidade das aulas e como alternativa aos impactos no calendário das instituições de ensino. Nesse formato, os professores tiveram que reformular todo o planejamento e passaram a utilizar diferentes softwares e aplicativos, ferramentas desconhecidas por muitos, o que gerou a necessidade de capacitação. Dito isso, o modelo de ensino remoto requereu mais horas de preparação e atuação por parte das professoras.

Os resultados da pesquisa revelaram que as professoras tiveram sua qualidade de vida afetada à medida que o formato de ensino passou a ser realizado sem sair de casa e 
misturado aos afazeres domésticos, aos cuidados familiares e de si, papéis que se evidenciaram no contexto do confinamento no lar, causando uma maior sensação de sobrecarga para as mulheres.

Além disso, os afazeres domésticos, mesmo que compartilhados com familiares, permanecem como responsabilidade destinada naturalmente à mulher, expressando que persiste uma desigualdade na divisão do trabalho que norteia o padrão de comportamento social. Essa afirmativa se justifica mediante a quantidade de horas semanais que as professoras pesquisadas dedicam às atividades domésticas e aos cuidados familiares. Cumpre salientar que a intensificação dessas atividades, em razão do contexto pandêmico, acarretou redução significativa do tempo destinado aos cuidados de si.

O tempo investido para o lazer também foi impactado, as professoras, em sua maioria, não conseguiram realizá-lo de forma satisfatória, com limitações intensificadas pela pandemia que se somaram às demandas sociais. Dentre as condições possíveis, as atividades que se aproximam do lazer envolvem os interesses virtuais, os manuais e os intelectuais, predominando o lazer virtual entre as mulheres professoras. Estas destacaram ter sido a tecnologia um recurso que possibilitou a socialização e o desenvolvimento pessoal, pelo acesso proporcionado a diferentes contextos e eventos que seriam pouco prováveis ou difíceis de se fazerem presentes antes da pandemia.

As professoras relataram que conseguiram incluir ou retomar algumas práticas de lazer que não estavam sendo possíveis antes da pandemia, dentre as quais se destacam os exercícios físicos, a culinária e o lazer virtual. Demonstrando, portanto, que a pandemia contribuiu para uma análise e reflexão acerca dos modos de vida, pondo em xeque os "antigos" hábitos e estabelecendo a necessidade de maior atenção e cuidado com o corpo e a alimentação. 
Para maioria das professoras investigadas, o ensino remoto provocou um cenário de desordem, de acúmulo de tarefas, maior do que o cotidiano de trabalho presencial, o que não nega que essa sobrecarga já se fazia presente. Fica evidente o quanto a realidade da mulher trabalhadora é desigual, desafiadora, exigindo embates e lutas constantes pelo reconhecimento dos diferentes papéis sociais exercidos no contexto feminino.

Espera-se que essa pesquisa contribua para que as mulheres percebam que não estão sozinhas, essa sensação de sobrecarga e o conflito em decorrência dos diferentes papéis assumidos é algo compartilhado por outras tantas mulheres. A falta de tempo para cuidar mais de si e para o seu desenvolvimento pessoal ainda permanece como uma constância. A sensação é que a naturalização das sobrecargas e o reduzido tempo para viver o lazer permanecem inalterados ao longo do tempo, mesmo com tantas transformações e conquistas femininas, se configurando como desumano e contraditório frente a representatividade crescente da mulher na sociedade.

Não se pretende encerrar a discussão, sugere-se que novos estudos abordando a temática do lazer de mulheres em diferentes contextos de atuação, profissões e condições de vida sejam desenvolvidos a fim de ampliar a percepção das implicações no tempo social no período de pandemia, além de contribuir para a reflexão sobre a divisão desigual do trabalho e suas repercussões para o tempo social das mulheres.

\section{REFERÊNCIAS}

ALVES, L. Educação remota: entre a ilusão e a realidade. Interfaces Científicas, Aracaju, v. 8, n. 3, p. 348-365, 2020. Disponível em: http://periodicos.set.edu.br/index.php/educacao/article/view/9251/4047. Acesso em: 01 jul. 2020.

BARDIN, L. Análise do conteúdo. Lisboa: Edições 70, 2011. 
BATISTA, E. B. S. Home office na educação: um estudo sobre o trabalho remoto de professores em tempos de pandemia. Monografia (Especialização) - Curso de Administração, Centro de Ciências Sociais Aplicadas, Departamento de Ciências Administrativas, Universidade Federal do Rio Grande do Norte, Natal, 2020.

BEHAR, P. A. O Ensino Remoto Emergencial e a Educação a Distância. Rio Grande do Sul: UFRGS, 2020. Disponível em: http://www.ufrgs.br/coronavirus/base/artigo-oensino-remoto-emergencial-e-a-educacao-a--distancia/. Acesso em: 10 jul. 2020.

BRABO, T. S. A. M. Cidadania da mulher professora. São Paulo: Ícone, 2005.

BRASIL. Instituto Brasileiro de Geografia e Estatística (IBGE). PNAD Contínua 2019. Disponível em: http://www.ibge.gov.br/. Acesso em: 22 nov. 2020.

Resolução n ${ }^{\circ}$ 510, de 07 de abril de 2016. Dispõe sobre as normas aplicáveis a pesquisas em Ciências Humanas e Sociais. Brasília: Conselho Nacional de Saúde, 2016.

BRUSCHINI, M. C. A. Trabalho e Gênero no Brasil nos últimos dez anos. Cadernos de Pesquisa, v. 37, n. 132, p. 537-572, set./dez.2007. Disponível em: http://www.scielo.br/scielo.php?script=sci_abstract\&pid=S010015742007000300003\&1 ng=en\&nrm=iso\&tlng=pt. Acesso em: 10 jul. 2020.

CAMARGO, L. O. L. O que é lazer. 3. ed. São Paulo: Editora Brasiliense, 2003.

CHAMON, M. Trajetória de feminização do magistério: ambiguidades e conflitos. Belo Horizonte: Autêntica, 2005.

CLEMENTE, A. C. F.; STOPPA, E. A. Lazer doméstico em tempos de pandemia da COVID-19. Licere, v. 23, n. 3, p. 460-484, set. 2020. Disponível em: http://periodicos.ufmg.br/index.php/licere/article/view/25524. Acesso em: 20 out. 2020. DOI: http://doi.org/10.35699/2447-6218.2020.25524.

COELHO, Virginia Paes; SILVA, Camilla de Alvarenga; FORTES, Débora Cristina Bahia. Trabalho e maternidade no cotidiano de professoras do ensino superior. In: ENCONTRO NACIONAL DE PESQUISADORES EM SERVIÇO SOCIAL, 8., 2012, Juiz de Fora. Anais [...]. Juiz de Fora:CIBS, 2012, p. 1-16. Disponível em: http://www.cibs.cbciss.org/arquivos/TRABALHO\%20E\%20MATERNIDADE\%20NO $\%$ 20COTIDIANO $\% 20$ DE $\% 20$ PROFESSORAS\%20DO\%20ENSINO $\% 20$ SUPERIOR. pdf. Acesso em: 29 jul. 2020.

DUMAZEDIER, J. Sociologia empírica do lazer. São Paulo: Perspectiva/SESC, 1994.

FORMOSINHO, J. (coord.). Formação de professores: aprendizagem profissional e acção docente. Porto: Porto Editora, 2009.

GARCIA, A. B. Trabalho feminino em dose dupla: onde está o lazer? Motrivivência, $\mathrm{n}$. 32/33, p. 375-388, 2009. Disponível em: http://periodicos.ufsc.br/index.php/motrivivencia/article/view/2175-8042.2009n3233p375. Acesso em: 17 jul. 2020. 
GURGEL, T. Feminismo e luta de classe: história, movimento e desafios teóricopolíticos do feminismo na contemporaneidade. In: SEMINÁRIO INTERNACIONAL FAZENDO GÊNERO, 9., 2010, Florianópolis, 2010. Anais [...]. Florianópolis, 2010 p. $1-9$. Disponível em: www.mulheresprogressistas.org/AudioVideo/FEMINISMO\%20E\%20LUTA\%20DE\%2 0CLASSE.pdf. Acesso em: 10 jul. 2020.

HODGES, Charles et al.. The Difference Between Emergency Remote Teaching and Online Learning. EDUCAUSE Review, 2020. Disponível em: http://er.educause.edu/articles/2020/3/the-difference-between-emergency-remoteteaching-and-online-learning. Acesso em: 26 de junho de 2020.

MARCELlinO, N. C. Estudos do Lazer: uma introdução. Campinas: Autores Associados, 2012.

MARTINS, R. X. A COVID- 19 e o fim da Educação a Distância: um ensaio. Revista de Educação a Distância, v. 7, n. 1, p. 242-256, 2020. Disponível em: http://www.aunirede.org.br/revista/index.php/emrede/article/view/620. Acesso em: 26 jun. 2020.

MARUANI, M. La calificación, uma construcción social sexuada. Economía y Sociologia Del Trabajo, Madrid, n. 21-22, p. 41-50, 1993. Disponível em: http://dialnet.unirioja.es/servlet/articulo?codigo=125255. Acesso em: 14 jul. 2020.

MONTENEGRO, G. M.; QUEIROZ, B. S.; DIAS, M. C. Lazer em Tempos de Distanciamento Social: Impactos da Pandemia de Covid-19 nas Atividades de Lazer de Universitários na Cidade de Macapá (AP). Licere, [S. l.], v. 23, n. 3, p. 1-26, 2020. Disponível em: http://periodicos.ufmg.br/index.php/licere/article/view/24785. Acesso em: 27 out. 2020. DOI: http://doi.org/10.35699/2447-6218.2020.24785.

MORAES, R. F. Prevenindo conflitos sociais violentos em tempos de pandemia: garantia da renda, manutenção da saúde mental e comunicação efetiva. IPEA: Diretoria de Estudos e Políticas do Estado, das Instituições e da Democracia. 2020. Disponível em: https://repositorio.ipea.gov.br/handle/11058/9836. Acesso em: 02 out. 2020.

NÓVOA, A. Os professores e as histórias da sua vida. In: NÓVOA, Antônio. (Org.). Vidas de Professores. 2. ed. Porto: Porto Editora, 2007.

OLIVEIRA, A. L. A espacialidade aberta e relacional do lar: a arte de conciliar maternidade, trabalho doméstico e remoto na pandemia de COVID-19. Revista Tamoios, São Gonçalo, v. 16, n. 1, ed. especial, p. 154-166, 2020. Disponível em: http://www.e-publicacoes.uerj.br/index.php/tamoios/article/view/50448/33479. Acesso em: 20 out. 2020.

OLIVEIRA, F. A.; QUEIROZ, F. M.; DINIZ, M. I. Divisão sexual do trabalho entre homens e mulheres no contexto da pandemia da COVID 19. Revista Inter-Legere, v. 3 , n. 28, p. c21486, 2 set. 2020. Disponível em: http://periodicos.ufrn.br/interlegere/articles/view/21486. Acesso em: 10 out. 2020.

PORTO, D. Trabalho doméstico e emprego doméstico: atribuições de gênero marcadas pela desigualdade. Revista Bioética, v. 16, n. 2, p. 287-303, 2008. Disponível em: 
http://revistabioetica.cfm.org.br/index.php/revista_bioetica/article/view/74. Acesso em: 06 jul. 2020.

PRONOVOST, G. Introdução à sociologia do Lazer. São Paulo: Editora Senac, 2011. Tradução: Marcelo Gomes.

SAMPIERI, R. H.; COLLADO, C. F.; LUCIO, M. P. B. Metodologia da pesquisa. 5. ed. Porto Alegre: Penso, 2013.

SCHWARTZ, G. M.; MOREIRA, J. C. C. O ambiente virtual e o lazer. In: MARCELLINO, N. C. (org.) Lazer e cultura. Campinas: Editora Alínea, 2007, p. 149170.

SILVA, C. L.; BERGAMO, L. G.; ANTUNES, D.; PATREZE, N. S. Os dias entre o teto e o chão da casa: lazer e práticas corporais no contexto brasileiro em tempos da Covid-19. Licere, v. 23, n. 3, p. 57-92, set. 2020. Disponível em: http://pesquisa.bvsalud.org/portal/resource/pt/biblio-1129264?src=similardocs. Acesso em: 04 out. 2020. DOI: https://doi.org/10.35699/2447-6218.2020.25111

SOARES, C. A distribuição do tempo dedicado aos afazeres domésticos entre homens e mulheres no âmbito da família. Gênero, Niterói, v. 9, n. 1, p. 9-29, 2008. Disponível em: http://periodicos.uff.br/revistagenero/article/view/30951. Acesso em: 27 jul. 2020.

SOUZA, K. R. et al. Trabalho remoto, saúde docente e greve virtual em cenário de pandemia. Trabalho, Educação e Saúde, v. 19, 2020. Disponível em: http://www.scielo.br/scielo.php?script=sci_arttext\&pid=S198177462021000100401\&ln $\mathrm{g}=\mathrm{en} \& \mathrm{nrm}$. Acesso em: 01 out. 2020.

TARDIF, M.; LESSARD, C. O trabalho docente: elementos para uma teoria da docência como profissão de interações humanas. 7. ed. Petrópolis: Editora Vozes, 2012.

TEODORO, A. P. E. G et al. A Dimensão Tempo na Gestão das Experiências de Lazer em Período de Pandemia da Covid-19 no Brasil. Licere, [S. l.], v. 23, n. 3, p. 126-162, 2020. Disponível em: http://periodicos.ufmg.br/index.php/licere/article/view/25305 . Acesso em: 23 out. 2020 .DOI: http://doi.org/10.35699/2447-6218.2020.25305.

WERNECK, C. L. G; STOPPA, E. A.; ISAYAMA, H. F. Lazer e Mercado. Campinas: Papirus, 2001.

\section{Endereço das Autoras:}

Amanda Raquel Rodrigues Pessoa

Avenida Valdemiro Paz de Souza, 65, Mirandão

Crato - CE - 63.125-210

Endereço eletrônico: amandaraquel@ifce.edu.br

Marla Maria Moraes Moura

Rua João Dídio de Oliveira, 77, São José

Juazeiro do Norte - CE - 63.024-122

Endereço eletrônico: marla.moura @ifce.edu.br 
Isabel Maria Sabino de Farias

Rua Monsenhor Antero, 635, Cidade dos Funcionários

Fortaleza- CE - 60.822-475

Endereço eletrônico: isabelinhasabino@yahoo.com.br 